innate mechanism. One possibility not mentioned by the authors is that the baboons' social knowledge is based on statistical learning, in which relationships can be implicitly learned through the increased probabilities that certain dyads or triads are seen together or that certain sequences of calls are heard with greater frequency than others. This mechanism is different from typical associative learning in that it is rapid, does not require reward and can be used to generate rules. Under this scheme, any explanation of baboon social intelligence would be completely interdependent with the structure of the current social group and the interactions therein.

We reflexively attribute minds like ours to non-human agents. Cheney and Seyfarth are acutely aware of this and, with their clever field experiments and careful observations, they address important questions regarding the evolution of social cognition without succumbing to the almost irresistible temptation of anthropomorphizing. Their enthusiasm is obvious, and their knowledge is vast and expressed with great clarity. All this makes Baboon Metaphysics a captivating read. It will get you thinking - and maybe spur you to travel to Africa to see it all for yourself. Asif A. Ghazanfar is an assistant professor at the Neuroscience Institute, Department of Psychology, Princeton University, Princeton, NJ 08540, USA.

\title{
The atomic peacemaker
}

other educational institutions, the Hebrew University should regard it as one of its "noblest tasks to keep our people free from nationalistic obscurantism and aggressive intolerance".

This book also includes fascinating documentation of Einstein's private and public responses to the rise of Nazism, in the course of which he forged an influential exemplar of the morally engaged twentieth-century intellectual. Collaborating with other prominent activists such as Romaine Rolland, Sigmund Freud and Bertrand Russell, he continually expressed his hope that the principles taught by great Germans such as Kant and Goethe would some day "prevail in public life and the general consciousness". This goal required that scientists and other intellectuals would assume public responsibility as advocates of tolerance, rational discourse, non-violence and other humanistic values. Provoked by the accusation from the Prussian Academy that his public statements against fascism constituted "atroc-

\section{Einstein on Politics: His Private Thoughts and Public Stands on Nationalism, War, Peace, and the Bomb \\ edited by David E. Rowe and Robert \\ Schulmann \\ Princeton University Press: 2007.560 pp. $\$ 29.95, \notin 18.95$}

\section{Yaron Ezrahi}

As a German Jew who rose to be the most celebrated scientist since Newton, a pacifist triggered by the rise of Hitler to recommend the development of the atomic bomb, a cosmopolite driven by the fate of his people to support a Jewish nation state, or as an émigré to America who supported socialist ideas in the time of McCarthyism, Einstein was often at the centre of clashing ideologies. A solitary individual who became trapped by the limelight of the world stage, Einstein was reluctantly forced to become an activist. Thus, Einstein on Politics is a goldmine for readers interested in Einstein as an engaged intellectual of his era.

Editors David E. Rowe and Robert Schulmann have done an excellent job of collecting, thematically assembling and historically contextualizing Einstein's private letters and public statements on the great political issues of his time. The book is also a fascinating record of Einstein's private thoughts and public stance on the reception of the relativity revolution. Included here are his reaction to the virulent anti-Semitic, anti-relativity German scientists, his tortured relations with the Prussian Academy of Sciences after the rise of the Nazis and his later expressed identification with Galileo for his struggle "to overcome the anthropocentric and mythical thinking of his contemporaries and to lead them back to an objective and causal attitude towards the cosmos".

Einstein's statement in 1921 that "my Zionism does not preclude cosmopolitan views" could serve as the motto for the vast sections in this book documenting his engagement

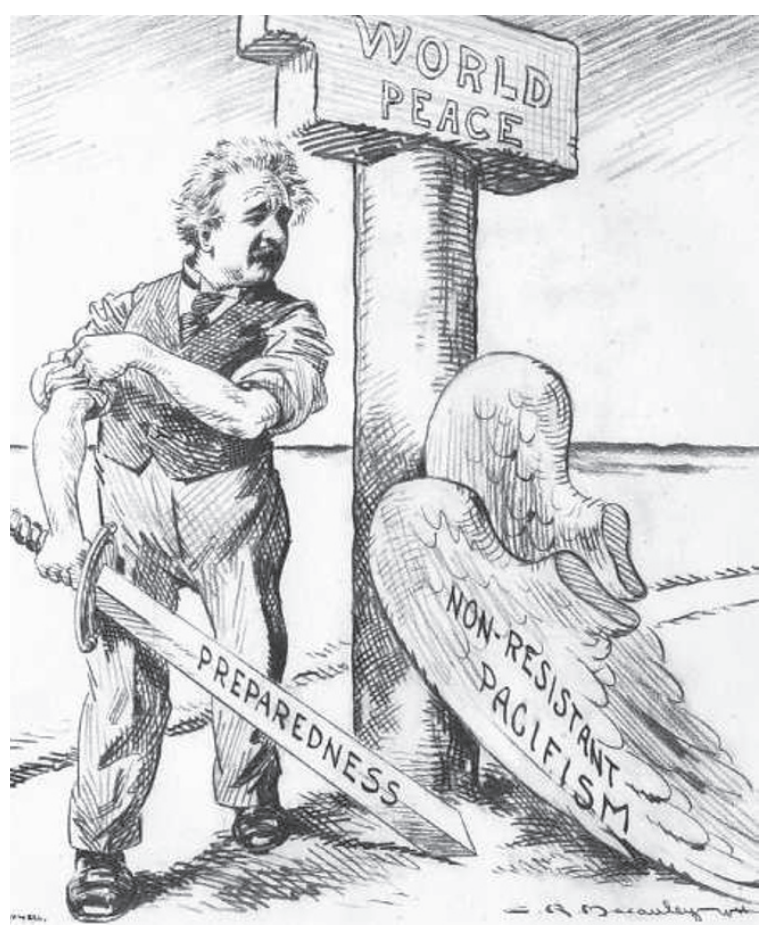

Einstein takes up the sword against fascism in this 1933 cartoon from the Brooklyn Eagle.

with the fate of Jews. His efforts to reconcile his cosmopolitanism and Zionism found particularly clear expression in his deep engagement with the founding of the Hebrew University of Jerusalem in 1925. Einstein regarded a Hebrew university as a vital part of a Jewish renaissance in Palestine and also as a necessary place for gifted Jewish youths barred by anti-Semitism from many European universities. Whereas the inclusion of 'Hebrew' in the name of the university implied a commitment to creating a Jewish home, Einstein had great faith in the mission of the university as an international academic institution. In a statement in March 1925, Einstein insisted that "Jewish nationalism is today a necessity" and that, together with ity-mongering against the German people", Einstein insisted on the moral responsibility of intellectuals to speak out against $\stackrel{\sim}{\dot{u}}$ violent nationalism. When urged by the German physicist Max Von Laue to exercise some restraint, he responded "Does not such restraint signify a lack of responsibility? Where would we be had men like Giordano Bruno, Spinoza, Voltaire and Humboldt thought and behaved in such a fashion?"

Einstein's impact on the relations between science, politics and freedom, however, transcends his record as a public intellectual. Ironically, the unintended wider cultural legacy of his physics worked against his commitment to democratic values and his faith in the mission of scientists to publicly combat violence and irrational politics.

In a letter to Rolland in August 1917, Einstein insisted that "only facts can dissuade the majority of the misled from their delusion". But Einstein's concept of facts, as expressed in his exchange with the French philosopher Henri Bergson, was rather esoteric. Failing to appreciate the importance of common-sense realism as the basis of democratic public discourse, he did not seem to anticipate that the shift from newtonian to einsteinian physics would widen the gap between authoritative scientific knowledge and lay opinion. His liberal-democratic commitment was contradicted by his view that "naive realism", the belief that "things 'are' as they are perceived by us through our senses", was a "plebian illusion". Deeply concerned about the turning of the public into a herd in the country of Kant and Goethe, he also failed to see that the public in democratic 
societies is not exactly moved by rational arguments free from rhetoric and theatricality.

In the final analysis, when Einstein thought or spoke about democracy, he seemed to have focused on conditions for the freedom and creativity of the individual rather than the group. Hence, much more important than all the things he said and wrote was his personal example as a scientist. By demonstrating the powers of one person's mind to revolutionize the view of the cosmos, Einstein reaffirmed the value of free individual thinking in resisting group-mind and coerced opinion - and therefore sustained the possibility that the majority could be wrong.

Yaron Ezrahi is a professor of political science at the Hebrew University of Jerusalem, Mount Scopus, Jerusalem 91905, Israel.

\section{Nervous systems made simple}

\section{An Introduction to Nervous Systems by Ralph Greenspan \\ Cold Spring Harbor Laboratory Press: 2007. 200 pp. \$45, £26.99}

\section{Eve Marder}

Until I saw pieces of giant squid in a fish market in Chile, I somehow hadn't appreciated that giant squids were really giant. Ralph Greenspan's An Introduction to Nervous Systems will similarly enlighten many of its readers on the wonders to be found through the study of invertebrate nervous systems and the behaviours they control. Furthermore, it is an eloquent mixture of fundamental neuroscience and evolutionary biology. Greenspan uses a variety of invertebrate animals to describe the fundamental processes of nervous-system function and by placing the basics of neuronal signalling in their functional contexts, he casts this information in evolutionary terms.

The savvy and sophisticated neuroscientist will find themselves learning about evolution; the evolutionary biologist will be led through a remarkably clear exposition of ion channels and action potentials, the fundamental elements of nervous activity. Smart high-school students will find an accessible and engaging account that reveals the magic and mysteries of nervoussystem function in a wide range of animals. The book will be especially useful as a text for university-level courses wishing to provide students without previous knowledge of neuroscience a broad context with which to understand how nervous systems generate behaviour.

Greenspan manages to be a scholar without being a pedant. Each chapter, which starts with an apt quotation from the classics, has a specific focus, and examples are chosen with finesse. Greenspan introduces the fundamentals of ion-channel structure and function using the swimming behaviour of the unicellular Paramecium. He continues with the escape response of jellyfish and includes a remarkable tidbit of cellular electrophysiology that I was unaware of: jellyfish neurons that generate either a low-amplitude calcium-dependent or a highamplitude sodium-dependent action potential to trigger a slow or rapid behavioural response, respectively.

Greenspan introduces neuromodulation in the context of the behavioural sensitization of the gill-withdrawal response of the sea slug Aplysia californica. This is the famous preparation used as a paradigm to study simple forms of learning, and here is my first quibble. I am, perhaps wrongly, sceptical of the generality of the results that are used to argue that some species of mollusc fail to show behavioural sensitization. I wonder whether assaying a different behaviour might reveal sensitization in the species that don't show it using the methods so effective for A. californica.
Circadian rhythms, flight, navigation, decision-making, courtship and mating in Drosophila are used to introduce the structure and function of networks important for complex behaviours. These sections of the book are presented with enough detail to do justice to the interplay of physiological processes important for an animal to function in the real world. Greenspan's scrupulous respect for understanding an animal's nervous system in terms of its real-world behaviour is apparent in his discussion of honeybee learning, where he relates the probable connection between the timing of stimuli in honeybee learning and the nature of the bees' foraging behaviour.

Greenspan clearly intended this book to be readable by and accessible to anyone. He succeeds admirably and it is an unadulterated delight to read. However, I confess to a modicum of regret that to avoid interrupting the flow, the references are placed at the back of the book, without citing which experimental result is found in a given reference. This will require readers to dig a little (not such a bad thing) to find some of the papers that they might wish to look at more carefully.

In addition to its use as a textbook, this book would make a wonderful present for your lawyer, banker, doctor or musician friend who retains a genuine curiosity about how animals interact with the world. Alternatively, you can take it to the beach or mountains this summer and use it to remind yourself to watch all kinds of creatures in their natural settings - while they and their environments still exist on our planet.

Eve Marder is the Victor and Gwendolyn Beinfield Professor of Neuroscience at Brandeis University, Waltham, Massachusetts 02454-9110, USA.

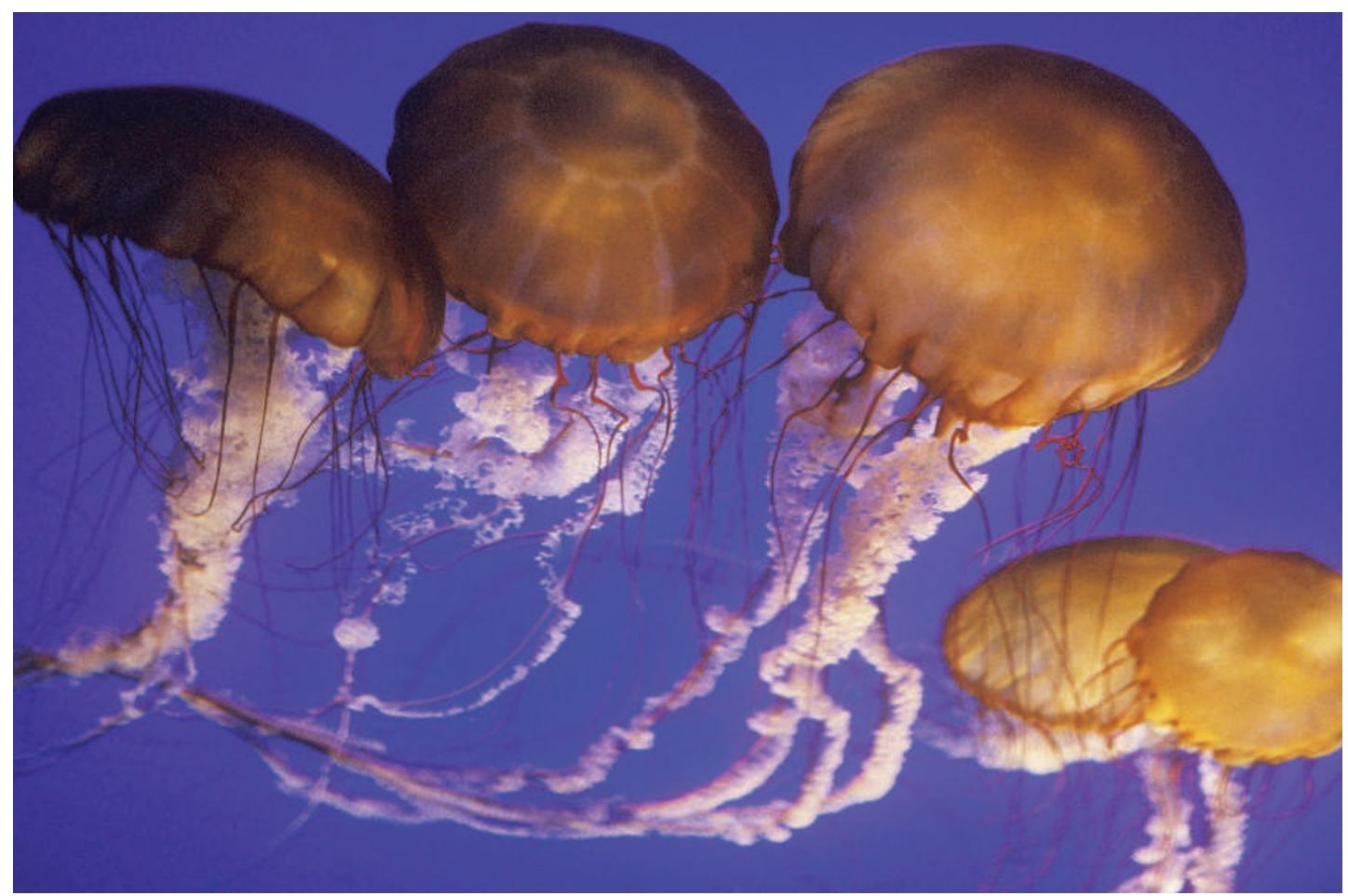

Even the simplest animal nervous systems, such as those of jellyfish, can spring suprises. 